\title{
ANALISIS LAJU KEAUSAN MAIN CONTACT STRIP PANTOGRAF KERETA PT MRT JAKARTA
}

\section{Aznawi Saiful Rifa'i dan Estu Prayogi}

Universitas Pancasila Jakarta, Indonesia

Email: aznawi13@gmail.com dan estupray05@gmail.com

\begin{tabular}{l}
\hline INFO ARTIKEL \\
\hline Diterima \\
13 Februari 2021 \\
Direvisi \\
21 Februari 2021 \\
Disetujui \\
15 Maret 2021 \\
\hline Keywords: \\
wear rate, main contact \\
strip pantograph, ogoshi \\
method wear test
\end{tabular}

\begin{abstract}
ABSTRAK
Maintenance and examination on pt MRT Jakarta train pantograph is done every month. In order to keep the train facilities always viable for operation, there needs to be a reference time for replacement of the main contact strip. The minimum thickness allowed for the main contact strip at this time is $5 \mathrm{~mm}$. While the thickness of the new main contact strip is $17 \mathrm{~mm}$. The purpose of this study was to determine the difference in the level of wear that would occur in accordance with the conditions in the field. Wear rate test using Ogoshi method with speed variant and glide distance variant. From the results of the research conducted, it can be concluded that the greater the speed, the higher the wear rate. The farther the glide distance, the lower the wear rate. The wear rate that occurs in the field is different from the wear rate in the Lab,
\end{abstract}

\begin{abstract}
ABSTRAK
Perawatan dan pemeriksaan pada pantograf kereta PT MRT Jakarta dilakukan setiap satu bulanan. Guna menjaga agar sarana kereta selalu layak operasi, perlu adanya acuan waktu penggantian main contact strip. Tebal minimum yang dibolehkan untuk main contact strip pada saat ini adalah $5 \mathrm{~mm}$. Sedangkan tebal main contact strip baru adalah $17 \mathrm{~mm}$. Tujuan dari penelitian ini adalah untuk mengetahui perbedaan tingkat keausan yang akan terjadi sesuai dengan kondisi yang ada di lapangan. Dilakukannya uji laju keausan menggunakan metode Ogoshi dengan varian kecepetan dan varian jarak luncur. Dari hasil penelitian yang dilakukan dapat disimpulkan bahwa semakin besar kecepatan maka tingkat keausan semakin tinggi. Semakin jauh jarak luncur maka semakin kecil tingkat keasusan. Laju keausan yang terjadi dilapangan berbeda dengan laju keausan di Lab.
\end{abstract}

Kata Kunci:

laju keausan, main contact strip pantograf, uji keausan metode ogoshi 


\section{Pendahuluan}

Pada era yang maju ini teknologi di bidang perkeretaapian terus berkembang. Banyak negara-negara maju yang mengembangkan perkeretaapian otomatis atau tanpa masinis (driverless). Salah satu alasan yang menjadikan perkeretaapian terus berkembang karena perkeretaapian merupakan transportasi yang dapat mengangkut penumpang secara masal (Kusumaningrum \& Asfirotun, 2013). Beberapa keunggulan perkeretaapian dibandingkan dengan moda transportasi lain, diantaranya perkeretaapian mampu memindahkan orang dan barang secara masal dengan selamat, aman, nyaman, cepat, efektif, efisien, dan tepat waktu (Istiantara, 2019).

KRL merupakan kereta rel listrik yang memiliki penggerak sendiri dimana sumber tenaganya dari listrik (Muhamad et al., 2019). Jakarta merupakan salah satu kota dengan tingkat perkembangan transportasi cukup pesat, salah satunya adalah KRL MRT Jakarta. MRT Jakarta diharapkan menjadi transportasi yang tepat waktu, aman, nyaman, dan selamat (Bintari \& Pandiangan, 2016). Menurut penjelasan UndangUndang Republik Indonesia No. 23 Tahun 2007 tentang Perkeretaapian, selamat adalah perjalanan kereta api terhindar dari kecelakaan akibat faktor internal (Syafirati, 2014).

Dalam peraturan perundang-undangan mengenai kehandalan sarana perkeretaapian telah diatur bahwa sarana perkeretaapian harus dilakukan perawatan berkala untuk menjaga kehandalan dari sarana KRL itu sendiri agar layak untuk dioperasikan (Aisyah et al., 2019), karena jika terdapat kerusakan atau kegagalan dalam sarana akan mengganggu perjalanan dan ketepatan waktu, untuk itu kereta harus melakukan perawatan dan pemeriksaan secara periodik sesuai standar yang berlaku. Ada beberapa jenis perawatan berkala (periodic) yang dilakukan diantaranya yaitu perawatan harian (daily maintenance) yang dilakukan setiap tiga hari sekali, perawatan bulanan (monthly maintenance) yang dilakukan setiap bulan dan perawatan tahunan (overhaul) setiap 8 tahun sekali (Nanjo, 2018).

Salah satu komponen utama yang ada pada kereta adalah pantograf, karena fungsi dari pantograf adalah sebagai penghubung antara kabel tembaga dengan tegangan 1500 VDC menuju ke traksi motor kereta (Gohtami, 2018). Bagian dari pantograf yang berhubungan langsung dengan sumber tegangan listrik aliran atas yaitu main contact strip. Pada saat kereta melaju akan terjadi gesekan antara main contact strip dengan kabel listrik aliran atas. Gaya gesek ini mengakibatkan berkurangnya material pada main contact strip atau disebut juga dengan aus, retak, bocor dan korosi merupakan penyebab dari suatu kerusakan komponen (Malau \& Khasani, 2013). Beberapa faktor yang mempengaruhi keausan yaitu sifat dari material, kekasaran dari material, koefisien gesek, dan faktor pembebanan atau gaya tekan dari pantograf (Besihi et al., 2013).

Perawatan bulanan pantograf yang dilakukan adalah pemeriksaan secara visual dan pemeriksaan fungsi kerja, selanjutnya pembersihan pada bagian pantograf, pengukuran tinggi carbon contact strip, pengukuran gaya tekan pegas, dan penggantian komponen jika diperlukan (Bruni et al., 2015). Pengukuran bertujuan untuk melihat kondisi aktual dari carbon contact strip (SINAGA, 2020). Hasil pengukuran yang didapat harus masuk dalam standar yang sudah ditentukan. 
Proses penggantian main contact strip kurang efektif jika dilakukan pada saat perawatan harian (Permana et al., 2019). Jika keausan terjadi sebelum jadwal perawatan bulanan berikutnya maka sarana dianggap tidak layak operasi dan tidak boleh jalan. Maka untuk menjaga layak operasi harus menjaga standar nilai-nilai minimum selama satu bulan berikutnya sampai masuk periode perawatan bulanan (Soehodho, 2017). Kemungkinan yang terjadi yaitu main contact strip mencapai batas minimum atau habis ditengah operasional. Untuk itu, perlu adanya analisis mengenai masa pakai penggunaan main contact strip.

Pada penelitian ini akan dilakukan pembuatan 3 (tiga) spesimen uji yang mengacu pada standar ASTM G99-04, kemudian pengujian pada main contact strip dengan menggunakan metode Ogoshi. Pengujian dilakukan dengan mengacu pada standar ASTM G99-95. Data yang sudah didapat dari hasil pengujian laju keausan dan data-data yang diperoleh di lapangan kemudian dianalisis untuk mendapatkan hasil laju keausan pada masing-masing data. Dari penelitian diatas penulis ingin mencoba membuat sebuah penelitian "Analisis Laju Keausan Main Contact Strip Pantograf Kereta PT MRT Jakarta". Tujuan akhir dalam penelitian ini adalah mengetahui laju keausan dari main contact strip pantograf kereta MRT Jakarta dan mengetahui pengaruh laju keausan terhadap masa pakai dari main contact strip pantograf kereta MRT Jakarta.

\section{Metode Penelitian}

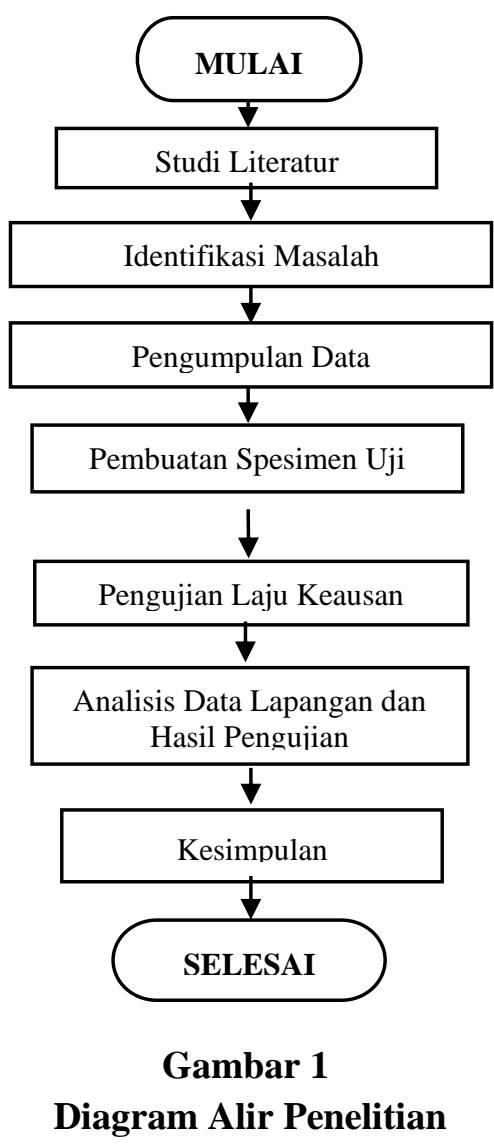


Bahan yang digunakan dalam eksperimen uji keausan ini adalah main contact strip pada KRL MRT Jakarta dengan jenis carbon metalized. Pemilihan bahan dilakukan pada KRL MRT setelah main contact strip telah beroperasi dan bagian yang digunakan merupakan bagian yang masih utuh dan bagus. Setelah memilih bahan untuk spesimen uji, selanjutnya dilakukan pembuatan spesimen dengan tujuan untuk mempermudah dalam analisis keausan yang sesuai dengan standar. Standar pembuatan spesimen uji mengacu pada standar ASTM G99-04 untuk pengujian keausan menggunakan metode pin-on-disk.

1. Pengujian Laju Keausan

Keausan merupakan hilangnya material secara progresif atau perpindahan sejumlah material dari suatu permukaan akibat dari pergerakan relatif antara permukaan tersebut dan permukaan lainnya. Pengujian keausan merupakan suatu uji karakteristik fisik yang digunakan untuk mengetahui seberapa besar tingkat keausan benda terhadap gesekan atau goresan. Uji keausan dilakukan dengan cara menghitung lebar keausan dari spesimen. Pengujian laus keausan pada main contact strip menggunakan metode Ogoshi yang mengacu pada standar ASTM G99-95a.

Rumus nilai keausan spesifik:

Keterangan:

$$
\mathrm{Ws}=\frac{B \times B o^{3}}{12 \times r \times X} \frac{m m^{3}}{m}
$$

$\mathrm{B}=$ lebar piringan pengaus $(\mathrm{mm})$

Bo = lebar keausan pada benda uji $(\mathrm{mm})$

$\mathrm{r} \quad=$ jari-jari piringan pengaus $(\mathrm{mm})$

$\mathrm{X}=$ jarak tempuh pada proses pengausan $(\mathrm{m})$

Ws = keausan spesifik $\left(\mathrm{mm}^{3} / \mathrm{m}\right)$

2. Analis Data Lapangan dan Hasil Pengujian

Data yang diperoleh dari hasil pengujian laju keausan dan di lapangan kemudian dianalisis untuk mendapatkan hasil laju keausan pada masing-masing data. Selanjutnya membandingkan hasil pengujian dengan hasil analisis yang terjadi di lapangan. Analisis keausan dilihat dari perubahan massa yang terjadi pada pin antara sebelum dan sesudah pin dilakukan pengujian. Hasil analisis dimasukkan kedalam tabel untuk mempermudah penelitian. 


\section{Hasil dan Pembahasan}

1. Perhitungan Analisis di Lapang

\section{Tabel 1}

Pengukuran Pantograf

\begin{tabular}{ccccc}
\hline Pantograf & $\begin{array}{c}\text { Tinggi aus } \\
(\mathbf{m m})\end{array}$ & $\begin{array}{c}\text { Volume aus } \\
\left(\mathbf{m m}^{\mathbf{3}}\right)\end{array}$ & $\begin{array}{c}\text { Jarak tempuh } \\
(\mathbf{m})\end{array}$ & $\begin{array}{c}\text { Keausan } \\
\left(\mathbf{m m}^{\mathbf{3}} \mathbf{m}\right)\end{array}$ \\
\hline 1 & 3,885 & $69.230,7$ & 8.614 .000 & 0,00804 \\
\hline 2 & 3,503 & $62.414,6$ & 8.614 .000 & 0,00725 \\
\hline 3 & 3,420 & $60.944,4$ & 7.854 .800 & 0,00776 \\
\hline 4 & 3,5025 & $62.414,55$ & 7.854 .800 & 0,00795 \\
\hline
\end{tabular}

Sumber: penelitian analisis laju keausan main contact strip pantograf kereta PT MRT Jakarta

Berdasarkan tabel 1, terlihat perbedaan hasil keausan dari pantograf 1 hingga pantograf 4 . Keausan tertinggi terlihat pada pantograf 1 dengan nilai 0,00804 dan keausan terendah terdapat pada pantograf 3 dengan nilai 0,00776. Hal ini menunjukan bahwa keausan dipengaruhi oleh tinggi aus, volume aus dan jarak tempuh.

2. Perhitungan Laju Keausan dari Hasil Lab

Pengujian dilakukan dengan acuan kondisi yang ada di lapangan yang kecepatan dan jarak tempuh antar stasiunnya tidak sama, maka perlu dilakukan beberapa varian kecepatan dan varian jarak luncur.

\section{Tabel 2}

\section{Laju Keausan Jarak Luncur 100 m-Varian Kecepatan}

\begin{tabular}{|c|c|c|c|c|c|c|}
\hline Kecepatan & $\begin{array}{c}\text { Beban } \\
\text { (Po) }\end{array}$ & $\begin{array}{c}\text { Jarak } \\
\text { luncur } \\
(\text { lo) }\end{array}$ & $\begin{array}{c}\text { Lebar } \\
\text { piringan } \\
\text { (B) }\end{array}$ & $\begin{array}{c}\text { Jari-jari } \\
\text { piringan } \\
\text { (r) }\end{array}$ & $\begin{array}{c}\text { Lebar } \\
\text { keausan } \\
\text { (Bo) }\end{array}$ & $\begin{array}{c}\text { Keausan spesifik } \\
\text { (Ws) }\end{array}$ \\
\hline 0,94 & 3,16 & 100 & 3 & 15 & 1,92 & $1,179 \times 10^{-3}$ \\
\hline 1,97 & 3,16 & 100 & 3 & 15 & 2,02 & $1,374 \times 10^{-3}$ \\
\hline 2,91 & 3,16 & 100 & 3 & 15 & 2,10 & $1,544 \times 10^{-3}$ \\
\hline
\end{tabular}

Sumber: penelitian analisis laju keausan main contact strip pantograf kereta PT MRT Jakarta

Tabel 3

Laju Keausan Jarak Luncur 200 m-Varian Kecepatan

\begin{tabular}{ccccccc}
\hline Kecepatan & $\begin{array}{c}\text { Beban } \\
(\text { Po) }\end{array}$ & $\begin{array}{c}\text { Jarak } \\
\text { luncur } \\
(\mathbf{l o})\end{array}$ & $\begin{array}{c}\text { Lebar } \\
\text { piringan } \\
(\mathbf{B})\end{array}$ & $\begin{array}{c}\text { Jari-jari } \\
\text { piringan } \\
(\mathbf{r})\end{array}$ & $\begin{array}{c}\text { Lebar } \\
\text { keausan } \\
(\mathbf{B o})\end{array}$ & $\begin{array}{c}\text { Keausan } \\
\text { spesifik } \\
(\mathbf{W s})\end{array}$ \\
\hline $\mathbf{0 , 9 4}$ & 3,16 & 200 & 3 & 15 & 2,21 & $0,899 \times 10^{-3}$ \\
\hline $\mathbf{1 , 9 7}$ & 3,16 & 200 & 3 & 15 & 2,23 & $0,924 \times 10^{-3}$ \\
\hline $\mathbf{2 , 9 1}$ & 3,16 & 200 & 3 & 15 & 2,65 & $1,551 \times 10^{-3}$ \\
\hline
\end{tabular}

Sumber: penelitian analisis laju keausan main contact strip pantograf kereta PT MRT Jakarta 


\section{Tabel 4}

\section{Laju Keausan Jarak Luncur 400 m-Varian Kecepatan}

\begin{tabular}{|c|c|c|c|c|c|c|}
\hline Kecepatan & $\begin{array}{c}\text { Beb } \\
\text { an } \\
(\mathbf{P o})\end{array}$ & $\begin{array}{c}\text { Jarak } \\
\text { luncur } \\
(\text { lo) }\end{array}$ & $\begin{array}{c}\text { Lebar } \\
\text { piringan } \\
\text { (B) }\end{array}$ & $\begin{array}{c}\text { Jari-jari } \\
\text { piringan } \\
\text { (r) }\end{array}$ & $\begin{array}{c}\text { Lebar } \\
\text { keausan } \\
\text { (Bo) }\end{array}$ & $\begin{array}{c}\text { Keausan } \\
\text { spesifik } \\
(W s)\end{array}$ \\
\hline 0,94 & 3,16 & 400 & 3 & 15 & 2,24 & $0,468 \times 10^{-3}$ \\
\hline 1,97 & 3,16 & 400 & 3 & 15 & 2,69 & $0,811 \times 10^{-3}$ \\
\hline 2,91 & 3,16 & 400 & 3 & 15 & 2,91 & $0,829 \times 10^{-3}$ \\
\hline
\end{tabular}

Sumber: penelitian analisis laju keausan main contact strip pantograf kereta PT MRT

Jakarta

3. Perbandingan Laju Keausan Terhadap Jarak Luncur dengan Varian Kecepatan

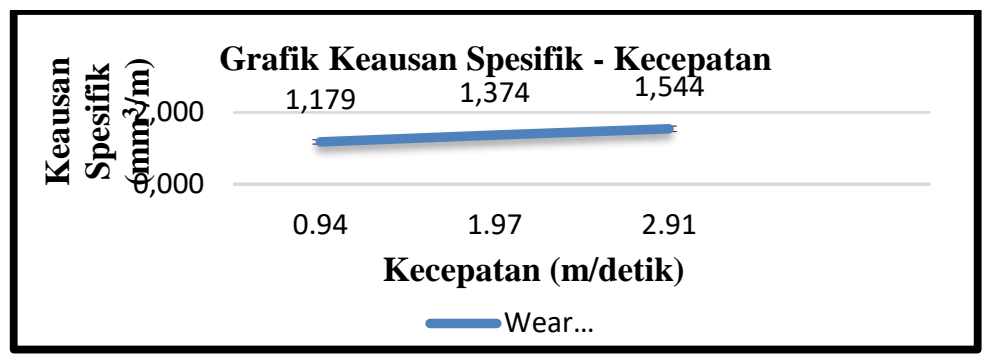

Grafik 1

Laju Keausan-Kecepatan (Jarak Luncur 100m)

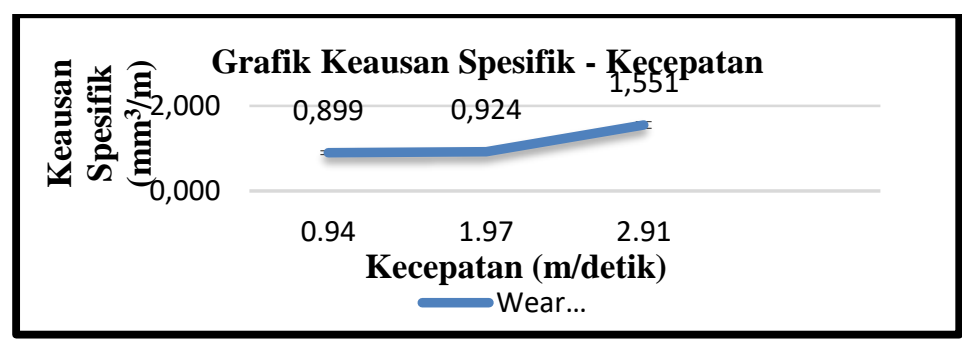

Grafik 2

Laju Keausan Spesifik-Kecepatan (Jarak Luncur 200m

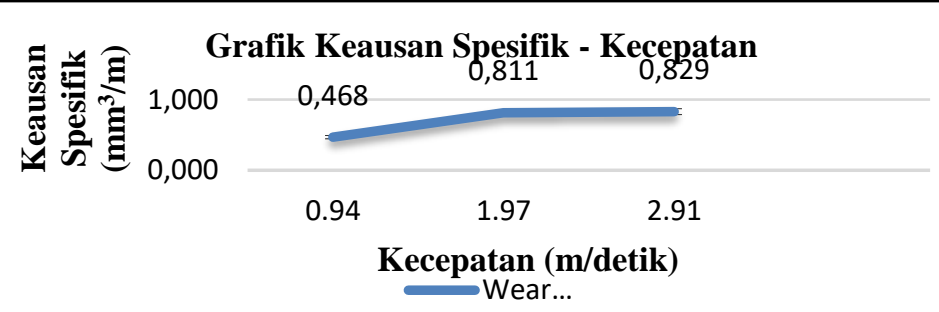

Grafik 3

Laju Keausan Spesifik-Kecepatan (Jarak Luncur 400m)

Secara teoritis, nilai wear rate akan semakin besar dengan semakin besarnya nilai kecepatan yang diberikan. Dari data yang ada, pengujian varian pertama 
hingga varian ketiga diperoleh hasil grafik yang hampir sama yaitu nilai laju keausan akan semakin tinggi jika kecepatan semakin tinggi. Karena besarnya kecepatan berpengaruh pada lebar keausan (Bo) yang dihasilkan. Besarnya kecepatan berdampak pada lebarnya keausan (Bo) pada spesimen sehingga semakin tinggi kecepatan yang diberikan semakin besar pula lebar keausan (Bo) pada spesimen. Hal ini sesuai dengan penelitian yang dilakukan oleh (Taufik et al., 2017).

4. Perbandingan Laju Keausan Terhadap Kecepatan dengan Varian Jarak Luncur

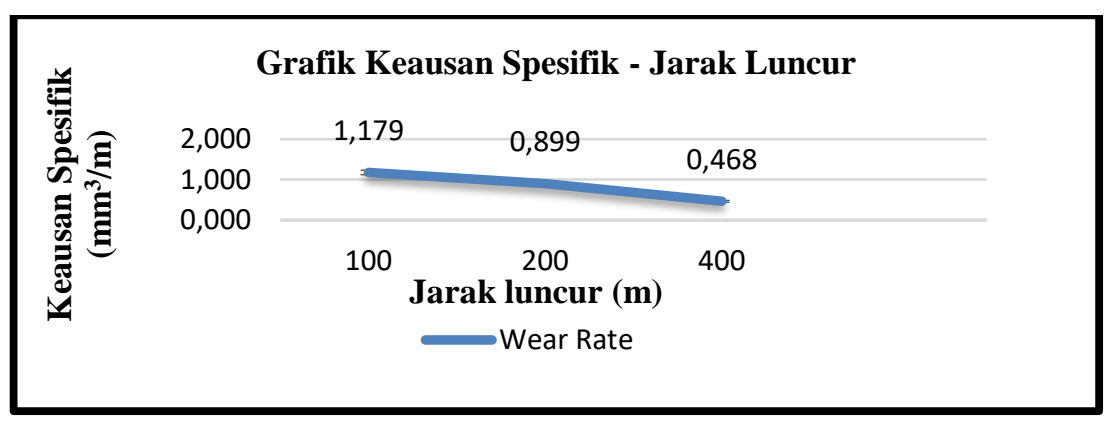

Grafik 4

Laju Keausan Kecepatan 0,94 M/Detik - Jarak Luncur

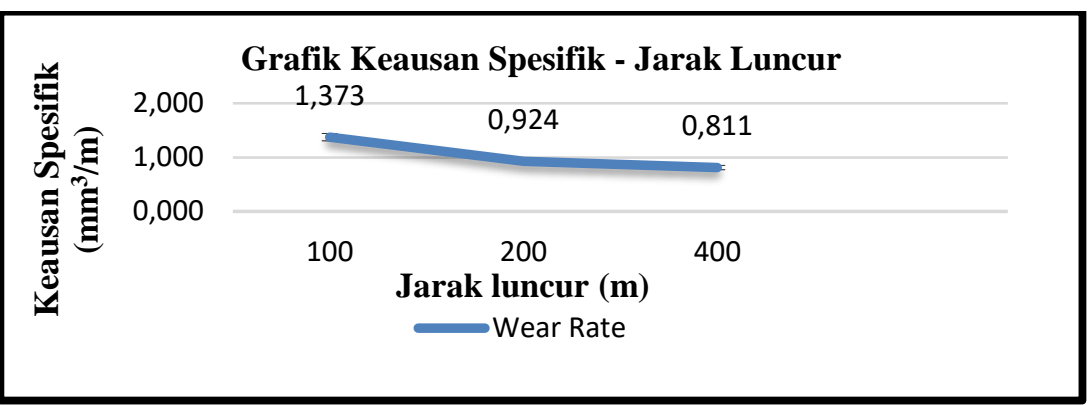

Grafik 5

Laju Keausan Kecepatan 1,97 M/Detik - Jarak Luncur

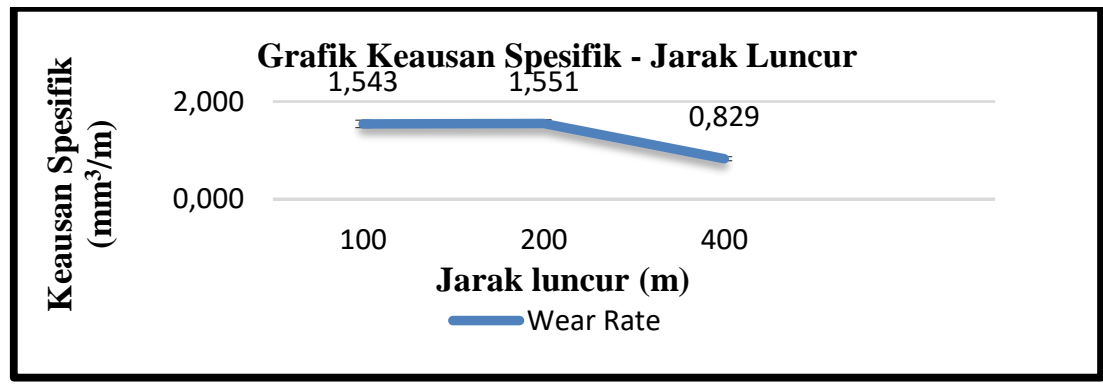

Grafik 6

Laju Keausan Kecepatan 2,91 M/Detik - Jarak Luncur

Dari hasil pengujian yang dilakukan dengan varian jarak luncur didapatkan laju keausan yang semakin menurun seiring jarak luncur yang semakin naik. Dengan 
begitu laju keausan berbanding terbalik dengan jarak luncur. Hal ini berbeda dengan penelitian yang dilakukan oleh Ahmad Taufik (Widianingrum \& Kaelani, 2012).

5. Perhitungan Masa Pakai (Life Time) dari Main Contact Strip

\section{Tabel 8}

Keausan Rata-rata di Lapangan

\begin{tabular}{cccccc}
\hline & $\begin{array}{c}\text { Pantograf } \\
\mathbf{1}\end{array}$ & $\begin{array}{c}\text { Pantograf } \\
\mathbf{2}\end{array}$ & $\begin{array}{c}\text { Pantograf } \\
\text { Pantograf }\end{array}$ & $\begin{array}{c}\text { Rata - } \\
\text { rata }\end{array}$ \\
\hline \multirow{2}{*}{ Keausan } & 0,00804 & 0,00725 & 0,00776 & $\mathbf{4}$ & 0,00795 \\
& $\mathrm{~mm}^{3} / \mathrm{m}$ & $\mathrm{mm}^{3} / \mathrm{m}$ & $\mathrm{mm}^{3} / \mathrm{m}$ & $\mathrm{mm}^{3} / \mathrm{m}$ & 0,00775 \\
& $\mathrm{~mm}^{3} / \mathrm{m}$ \\
\hline
\end{tabular}

Sumber: penelitian analisis laju keausan main contact strip pantograf kereta PT MRT Jakarta

Tabel 9

Keausan Rata-rata di Lab

\begin{tabular}{ccccccccccc}
\hline & Varian 1 & \multicolumn{3}{c}{ Varian 2 } & \multicolumn{1}{c}{ Varian 3 } & Rata - \\
\cline { 2 - 9 } & 2 & 3 & 1 & 2 & 3 & 1 & 2 & 3 & rata \\
\hline
\end{tabular}

$\begin{array}{lllllllllll}\text { Keausan } & 1,179 & 1,374 & 1,544 & 0,899 & 0,924 & 1,551 & 0,468 & 0,811 & 0,829 & 1,064\end{array}$

Sumber: penelitian analisis laju keausan main contact strip pantograf kereta PT

MRT Jakarta

Terdapat perbedaan antara hasil analisis lapangan dengan hasil analisis lab disebabkan oleh perbedaan kondisi pengujian di Lab yang tidak ditambah faktor eksternal sedangkan kondisi di lapangan terdapat faktor alam seperti hujan, panas matahari, debu, dan panas tegangan listrik.

\section{Kesimpulan}

Dari hasil pengujian yang dilakukan telah didapatkan data-data yang sudah dianalisis. Dari hasil analisis ini dapat disimpulkan bahwa laju keausan main contact strip yang ditinjau dari data lapangan yaitu $0,00775 \mathrm{~mm}^{3} / \mathrm{m}$ atau $7,75 \times 10^{-3} \mathrm{~mm}^{3} / \mathrm{m}$. Sedangkan laju keausan main contact strip yang ditinjau dari data lab yaitu $1,064 \times 10^{-3}$ $\mathrm{mm}^{3} / \mathrm{m}$ atau $0,001064 \mathrm{~mm}^{3} / \mathrm{m}$. Hasil analisis lapangan dengan hasil analisis lab berbeda yang disebabkan karena kondisi di lapangan berbeda dengan kondisi pengujian di lab. Laju keausan main contact strip di lab lebih kecil daripada laju keausan di lapangan, karena banyak faktor lain yang dapat mempengaruhi laju keausan misalnya hujan, panas gesekan, dan tegangan listrik. Masa pakai dari main contact strip jika ditinjau dari data lapangan yaitu main contact strip dapat digunakan selama 1.724 kali perjalanan (Stasiun Lebak Bulus-Stasiun Bundaran HI) atau 862 kali perjalanan pulang - pergi. Jika dalam perhitungan waktu maka main contact strip dapat digunakan selama 3,4 bulan. Sedangkan masa pakai main contact strip jika ditinjau dari data lab yaitu main contact strip dapat digunakan selama 12.561 kali perjalanan ( Stasiun Lebak Bulus - Stasiun Bundaran HI) atau 6.280 kali perjalanan pulang-pergi. Jika dalam perhitungan waktu maka main contact strip dapat digunakan selama 25 bulan. Masa pakai di lab lebih hemat 7 kali dibanding masa pakai di lapangan. 


\section{BIBLIOGRAFI}

aisyah, W. U. N., Salim, F., \& Sofyan, M. (2019). The Influence Of Service Quality And Price On The Interest Of Commuterline Krl Passengers. Ilomata International Journal Of Management, 1(1), 13-18.

Besihi, N. A., Darmanto, \& Syafa'at, I. (2013). Analisis Keausan Baja St60 Menggunakan Alat Tribotester Tipe Pin On Disc Dengan Variasi Kondisi Pelumas. Momentum, 9(2), 1-4.

Bintari, A., \& Pandiangan, L. H. S. (2016). Formulasi Kebijakan Pemerintah Tentang Pembentukan Badan Usaha Milik Daerah (Bumd) Perseroan Terbatas (Pt) Mass Rapid Transit (Mrt) Jakarta Di Provinsi Dki Jakarta. Cosmogov. Jurnal Ilmu Pemerintahan Issn, 2442, 5958.

Bruni, S., Ambrosio, J., Carnicero, A., Cho, Y. H., Finner, L., Ikeda, M., Kwon, S. Y., Massat, J.-P., Stichel, S., \& Tur, M. (2015). The Results Of The PantographCatenary Interaction Benchmark. Vehicle System Dynamics, 53(3), 412-435.

Gohtami, E. (2018). Evaluasi Dan Eksperimentasi Desain Modul, Pola Dan Sambungan Pada Konstruksi Bambu Dengan Sistem Pantograf.

Istiantara, D. T. (2019). Pengembangan Manajemen Sumber Daya Manusia Berbasis Kompetensi Guna Meningkatkan Kinerja Pegawai Dan Dosen Polikteknik Perkeretaapian Indonesia. Jurnal Perkeretaapian Indonesia (Indonesian Railway Journal), 3(2).

Kusumaningrum, A. E., \& Asfirotun, J. (2013). Analisis Kepuasan Pengguna Jasa Terhadap Kinerja Pt. Kereta Api Indonesia (Persero)(Krl Commuter Line Jakarta Kota-Bogor). Prosiding Pesat, 5.

Malau, V., \& Khasani. (2013). Karakteristik Laju Keausan Dan Kekerasan Dari Pack Carburizing Pada Baja Karbon Aisi 1020. Media Teknik, 30(3), 367-374.

Muhamad, A. T., Sukmadi, T., \& Winardi, B. (2019). Analisa Outage Cost Pada Operasi Kereta Rel Listrik Pt Kai Commuter Jabodetabek Tahun 2015. Transient: Jurnal Ilmiah Teknik Elektro, 7(3), 694-700.

Nanjo, D. (2018). Mass Rapit Transit Jakarta Contract Package 108 Project Training Material Of Pantograph And Master Controller. In Japan Railwe (Vol. 1, Issue 18).

Permana, T. L., Asmarany, A. I., \& Saputra, M. (2019). Empati Dan Perilaku Prososial Pada Mahasiswa Pengguna Kereta Rel Listrik. Jurnal Psikologi, 12(1), 1-10.

Sinaga, A. J. (2020). Analisis Laju Korosi Dan Kekerasan Baja Stainless Steel 316 L Dan Baja Karbon Rendah Dalam Larutan 10\% Nacl Terhadap Variasi Waktu.

Soehodho, S. (2017). Public Transportation Development And Traffic Accident 
Prevention In Indonesia. Iatss Research, 40(2), 76-80.

Syafirati, M. W. (2014). Perlindungan Konsumen Pengguna Jasa Transportasi Kereta Api Dalam Undang-Undang Nomor 23 Tahun 2007 Tentang Perkeretaapian.

Widianingrum, D. T., \& Kaelani, Y. (2012). Studi Eksperimental Laju Keausan (Specific Wear Rate) Resin Akrilik Dengan Penambahan Serat Penguat Pada Dental Prosthesis. Jurnal Teknik Its, 1(1), B125-B129. 
Aznawi Saiful Rifa'i dan Estu Prayogi 